Niniejsza publikacja jest dostępna na licencji Creative Commons. Uznanie autorstwa-Użycie niekomercyjne-Bez utworów zależnych 3.0 Polska. Pewne prawa zastrzeżone na rzecz autora. Zezwala się na wykorzystanie publikacji zgodnie z licencjapod warunkiem zachowania niniejszej informacji licencyjnej oraz wskazania autora jako właściciela praw do tekstu. Treść licencji jest dostęna na stronie: http://creativecommons.org/licenses/by-nc-nd/3.0/pl/

Lingwistyka Stosowana 17: 2/2016, 103-111

\author{
Anna UYTTERHAEGEN \\ University of Rzeszów \\ Education First London, United Kingdom
}

\title{
Cognitive Correlates of Bilingualism
}

\begin{abstract}
:
This article explores the extent to which two factors commonly said to influence the effectiveness with which learners acquiring a second language to a near-native level (thus achieving bilingualism) can also affect the learner's cognitive development. These factors are age and socio-cultural attitude. Beginning with an investigation of academic theories on correlations between bilingualism and cognitive faculties, the main focus of this article will be on the interpretation of studies involving bilingual subjects and modern arguments agreeing or contesting theories in this field which still suffers from an undeniable scarcity of practical data.
\end{abstract}

\section{Introduction}

In 1962, E. Peal and W.E. Lambert introduced the concept of 'balanced bilinguals', which significantly shifted the prevailing views on bilingualism (E. Peal/ W. E. Lambert 1962). Before their seminal article, bilingualism had been regarded as potentially deleterious to cognitive development, and had been associated with reduced performance in various cognitive tasks. However E. Peal and W.E. Lambert noticed that early studies had not matched bilingual and monolingual participants along several key dimensions, such as gender, age, socio-economic status, second-language proficiency, and urban-rural contexts. Noting the lack of academic rigor in previous studies E. Peal and W. E. Lambert found that when researching these external factors, bilingual participants significantly outperformed monolinguals on measures of verbal and nonverbal intelligence.

Since then, a body of evidence has accumulated in support of the assertion that bilingualism is associated with certain cognitive benefits. Despite this, however, there still remain certain pertinent questions relating to external factors that might play a role in the above-mentioned cognitive benefits. This article will thus begin with a brief review of certain cognitive benefits that have manifested themselves, noting in particular studies addressing executive control and metacognitive awareness. It will subsequently address a contentious point, which has been the extent to which metalinguistic awareness is increased in bilinguals. Recognising the importance of certain external factors such as age and socialization, this article will then address some of the factors that seem to confound studies looking at bilingualism. 


\section{Bilingualism and executive control}

Over the last few decades, there has been considerable evidence that bilinguals enjoy a greater degree of executive control over their monolingual peers. Explanations have generally suggested that bilinguals have increased executive control as a result of having to control their attention through selecting the target language. Effectively, research has claimed that the capacity to inhibit linguistic intrusions from another language has developed the bilinguals' general control mechanism, often reflected by a better performance on tasks involving conflicting information. Not all studies, however, reach the same conclusion, which raised doubt as to whether the results could be said to be significant.

J.B. Morton and S.N. Harper (2007) have argued that inconclusive studies on increased executive control in bilinguals were the outcome of mismatched participants from varying income brackets. Following this assertion, a recent study sought to determine whether comparing low socio-economic status (SES) groups would provide similar results, or whether a lower, as opposed to a higher SES, would result in differentiated cognitive outcomes in bilinguals and monolinguals in their general control mechanism. The study used a sample of 40 bilingual children and 40 monolingual children from low SES and subjected both participant groups to selective attention and interference suppression tests. In support of current evidence, the study found that low SES bilingual participants performed better in executive control tests than the monolingual control group.

In a separate study, E. Bialystok et al. (2007) sought to determine the effects of lifelong bilingualism on maintaining cognitive functioning and delaying the onset of dementia in old age. The hypothesis suggested that bilingualism increases a person's 'cognitive reserves' (i.e. the brain's ability to cope with increasing damage and still function) through 'sustained complex mental activity' (E. Bialystok et al. 2007: 459). Indeed, as bilingualism has shown to increase attention control in children and adults, the authors argue it will also contribute to a higher cognitive reserve and protect older adults from cognitive decline in dementia. Similar studies, which have sought to determine the impact of bilingualism on incidence of dementia, such as M. J. Valenzuela, and P. Sachdev (2006), strongly support the assertion that bilingualism engages the brain in a complex mental activity, such as a person's executive control mechanisms.

Another area, which has associated a positive connection between bilingualism and cognitive benefits, has been metacognitive awareness. Metacognitive awareness refers to an individual's ability to acknowledge one's own cognitive strategies in languageprocessing, or 'an awareness of one's own learning strategies and the mental activities required to self-regulate the learning process (O. Adescope et al. 2010). In a study designed to investigate metacognitive awareness, monolingual and multilingual preschoolers were exposed to two movie clips to explore the reactions to an exolingual situation of communication. The preschoolers were between the ages of 4 and 6 . The experimental design had an interlocutor engaged in a conversation with the preschooler after the movie clip in a different language to observe the children's reception of information. The results of the study confirmed the hypothesis that bilingual and multilingual children would outperform monolinguals in their inclination to continue 
communication with the actor instead of giving up exchange. Effectively, bilingual preschoolers utilized their awareness of existing language structures and adapted these to the exolingual communication. While understanding was limited, the amount of time spent trying to understand the communication suggests that these children are more aware of certain linguistic structures and concepts.

In a separate study, S. Ransdell et al. (2008) investigated metacognitive awareness in college students from a range of language experience backgrounds. The experimental design compared metacognitive awareness in college students as measured by selfreported ratings of reading, writing, speaking and listening skills. Monolingual, bilingual and multilingual students from America, Estonia and France read for comprehension and remembered sentence final words in a reading task in their own language. The results showed that multilingual and bilingual students had better metacognitive awareness of their language skills in working memory and reading than their monolingual peers, who have the same native language level. Similarly, C. Kemp (2007) explored the use of grammar learning strategies in 144 monolinguals, bilinguals and multilinguals. The hypothesis was very much consistent with the previous two studies and posited that multilinguals have enhanced grammar-learning strategies as a result of a betterdeveloped metacognitive awareness. In other words, individuals who are able to speak multiple languages are better able to discern the ways in which they use the forms and structure of language. C. Kemp (2007) used a background language questionnaire which consisted of 40 grammar-learning strategies on a 5-point Likert scale, and questions on other grammar acquisition strategies. The findings of the study suggested that bilinguals and multilinguals used significantly more grammar learning strategies, and used these more frequently than monolinguals. Interestingly, the study also suggested that multilinguals used more of the 40 grammar learning strategies and each additional language learned increased the frequency of these strategies.

\section{Bilingualism and metalinguistic awareness}

In the area of metalinguistic awareness, however, there has been more contention as to whether bilinguals have an increased metalinguistic awareness, defined as the ability to understand the underlying meaning of language from its form and structure. Certain studies on metalinguistic awareness and bilingualism have suggested that the ability to hold two languages concurrently allows for a deeper understanding of how language works. This however, has not been ubiquitously proven, and indeed there have been a range of studies, which indicate that certain cognitive advantages of bilinguals may only manifest themselves as a product of a particular combination of languages, the age of the subjects, or the particular style of instruction. E. Bialystok et al. (2003), for example, conducted three studies examining the development of phonological awareness in bilingual and monolingual pre-school children. While the two first studies provided inconclusive results, the third study, which included both phoneme substitution tasks and a phoneme segmentation task, indicated that English-Spanish bilinguals performed better at the segmentation task than the English speaking monolinguals. However, a second bilingual group consisting of children speaking English and Chinese, proved to do worse at both tasks than the Anglo-Spanish and monolingual groups. Studies in the 
past looking at metalinguistic awareness and bilingualism have generally indicated similar trends.

M. Bruck and F. Genesee (1995) compared English-speaking monolingual children with other Anglophone children attending French schools. The study was longitudinal and followed the children from kindergarten to first grade. Interestingly, while in kindergarten, the children in the French programs performed better on onset-rime segmentation tasks, the advantages disappeared in the first grade, replaced by an advantage in a syllable counting task. The results of the study suggested that while bilingual children seemed to have an advantage in kindergarten, the nature of the cognitive benefit, in this case metalinguistic awareness, may change over time due to several different factors such as type of language, age, and instruction. Indeed in $\mathrm{M}$. Bruck and F. Genesee's study, it was hypothesized that the structure of French phonology, making syllables more salient than English phonology, was the reason for this manifest advantage in the first grade.

G. W. Yelland et al. (1993) also found that certain metalinguistic advantages which bilingual children indicated in kindergarten, disappeared in the first grade. In this study, children were asked to make judgments of the sound structure of words by determining whether simple pictures depicted a long-named object (polysyllabic) or a short-named object (monosyllabic). They found that while bilinguals outperformed monolinguals in kindergarten, the advantage disappeared at the end of grade one. Also similar to M. Bruck, and F. Genesee, however, was the constant advantage of bilinguals in word recognition tasks. However, ultimately this area remains contentious as studies do not all demonstrate a clear advantage for bilingual children in regards to metalinguistic awareness as a whole. Additionally, the studies seem to underline the importance of taking into consideration context-specific variations, such as age, which might influence the perceived benefits of bilingualism.

\section{Bilingualism and creativity}

Likewise, it has been generally argued that bilingualism in children has positive results on that child's creative and divergent thinking. This assertion has equally been met with skepticism, with several studies claiming varying views. Divergent and convergent thinking may be seen as inherently similar but are fundamentally different in the cognitive mechanisms, which are used in each process. Divergent thinking has been exemplified by J.P. Guilford's et al. (1967) alternate uses task in which participants were asked to come up with as many possible uses for a pen as possible. In contrast, M.T. Mednick's (1962) remote associates task presented participants with three concepts, and the participants had to find a word that linked all three.

Divergent thinking is theorized as benefitting from a cognitive control state that prioritizes a minimum of local competition and top-down bias. In other words, the individual must be able to switch from one concept to the other with little resistance. Conversely, convergent thinking benefits from a strong top-down bias and local competition, so that the thinking is restricted to funneling particular concepts through. Past studies have suggested that bilinguals have an increased advantage on divergent thinking tasks (L.A. Ricciardelli 1992). More recently, however, these findings have been increasingly questioned. B. Hommel (2011) in particular claims that age might 
explain the apparent inconsistencies in the results. Indeed, a vast majority of studies looking at links between divergent thinking and bilingualism have used children as participants. The importance of this is underlined in the fact that both divergent and convergent studies have been shown to be mediated by the two major dopaminergic pathways in humans - the striatal and frontal pathway. These pathways are strongly affected by developmental factors and keep developing into early adulthood. Indeed, taking into account the wider literature on creativity, the variability noticed in individual creativity over a life span is congruent with the variability noticed in divergent and convergent thinking with bilingualism. The outcome of B. Hommel's (2011) study indicated that, as opposed to L.A. Ricciardelli's (1992), proficient bilinguals are stronger with convergent thinking because of the focused cognitive control state needed to manage two separate languages at once. While B. Hommel's study is congruent with most studies, which indicate that bilinguals outperform monolinguals in verbal fluency tests, it also goes against the expectation that bilingualism is associated with a greater degree of cognitive flexibility.

\section{Age and socio-cultural attitude as external factors to bilingualism}

Having noted discrepancies within various areas associating bilingualism and its cognitive correlates, two external factors in particular stand out: age and socio-cultural attitude. As aforementioned, socio-economic circumstances may heavily impact the extent to which bilinguals might exhibit advantages in cognitive processing. It also follows that socio-cultural attitudes towards bilingualism and the use of certain languages might impact results differently. These two factors are often heavily interconnected, and as such we will speak of age as both in and of itself important in assessing the cognitive correlates of bilingualism, but also as heavily dependent to the context of second language acquisition.

The last few decades have seen a considerable amount of work going into empirical research on the question of age and second language acquisition. While the neurocognitive development literature is highly useful in understanding how an individual becomes bilingual as a child and the impact it will have throughout their life, it is equally essential to uncover the outcome of becoming bilingual later in life. Indeed, while many bilingual children may have simply grown up in bilingual households, a vast number of individuals will have learned a second language at various other times, which in turn might affect the level of cognitive processing. In many cases, the age of acquisition (AoA) is understood as the age at which learners are immersed in the second language (L2) context, while the age of exposure (AoE) refers to situations in which the learner is exposed to the L2 language (such as a formal schooling environment, visits to an L2 country, contact with L2 native speakers, etc.).

In a survey of the data on the relationship between AoA and cognitive processing, D. Birdsong (2006) presents three differing paradigms, which suggest different outcomes based on critical periods of maturation. These periods effectively evidence studies which have indicated that at a certain age, SLA produces the best cognitive outcomes. The first of three observed effects of maturation shows a direct decline ceasing at a point of articulation coinciding with the end of maturation. The second suggests that the period leading up to maturation is where success is guaranteed and after 
which outcomes of SLA decline throughout old age. The third possibility, posited by J.S Johnson and E.L. Newport (1989), compounds the two first theories in what begins as an upper ceiling during which SLA is guaranteed success, and which declines until maturation is achieved, at which time the rate of success flat-lines and no further age effects are seen. The downward slope, according to this theory, begins before puberty. However, instead of finding the flat-lining after maturation, J.S. Johnson and E.L. Newport found random dispersion points indicating that the flattening feature of the age function is not present in the data. K. Hakuta and E. Bialystok (1994) later found a significant correlation using J. S. Johnson and E. L. Newport's data when putting the maturation period after 20 years. However, instead of finding a flat-line, they found a declining negative correlation of AoA for the late arriving group.

Thus, the conceptualisation of a 'critical period' in which SLA produces the best cognitive outcome remains contentious. While there is a general acceptance that there is a certain age at which the benefits of cognitive processing in SLA begin to decline, there have been wildly varying proposals suggesting when this 'peak learning time' will finish, varying from just after birth to late adolescence. A series of proposals by E.H. Lenneberg et al. 1967, M.H. Long 1990, S. Pinker 1994, T. Scovel 2000 and H.M. Seliger 1978 have posited that changes occur around puberty, however, there are divergences regarding whether these changes signal a critical period in the non-conventional sense (when the declines in performance begin), or in the conventional sense (when performance decline ceases). On the whole, it appears that little evidence from cognitive, brain volume or dopaminergic literature gives credence to this maturational account even if the literature does indicate a general decline in cognitive performance over time (D. Birdsong, 2006). As a result, certain theorists have underscored the importance of taking into account the socio-cultural context of SLA as an important external factor, which plays a critical role in determining the cognitive correlates of bilingualism.

In particular in socio-cultural studies and bilingualism, the notion of the 'zone of proximal development' (ZPD) has substantially impacted theorists in developmental psychology, education and applied linguistics. The most known definition of ZPD is often referenced to L.S. Vygotsky (1978:86) and is:

[...] the distance between the actual developmental level as determined by independent problem solving and the level of potential development as determined through problem solving under adult guidance or in collaboration with more capable peers [...]

As well as being generally important for education policy, ZPD is a crucial factor to be taken into account when determining the outcome of bilingualisation with regards to benefits in cognitive processing. Indeed, according to L.S. Vygotsky, learning is a process in which the learner acquires certain higher level cultural tools (i.e. language, literacy, numeracy, etc.) in order to navigate one's reality, which is embedded in a complex network of social symbols and artifacts. It follows then that each social environment will afford varying outcomes in terms of an individual's performance in SLA. ZPD has thus been spearheaded by various theoretical schools using elements of socio-cultural theory in order to both shape learning styles which might optimize a learning environment, but also as a means to explain certain inconsistencies which, for socio-cultural theorists, might be explained by the varying ways in which individuals are socialized into SLA. According to J.P. Lantolf and S.L. Thorne (2006), the three 
elements, which are of crucial concern in the process of acquiring a second language, may be summarized as 'mediation and regulation', internalisation and ZPD. Mediation and regulation summarises the view that all human activity does not directly relate with the world, but rather their cognitive activities are mediated through symbolic artifacts. Internalisation, on the other hand, is the mechanism by which 'interpersonal and personenvironment interaction both forms and transforms one's internal mental functions, as well as the role of imitation in learning and development' (J.P. Lantolf/ S.L. Thorne, 2006). Taking these three concepts, we begin to understand the importance one must associate, when analyzing the cognitive correlates of bilingualism, to the context and person-specific factors, which input directly into potential cognitive benefits of that person.

In particular, the effect of social interaction has been seen in the positive outcomes of increased motivation. In other words, the degree to which an individual exhibits increased performance has been argued to be attributable to a motivational drive, which may become salient through the socialization process. Following from this assertion, P. Cooper and D. McIntyre (1996) logically deduced that an effective learning environment with highly motivated students necessitates strong interpersonal interactions. These circumstances may thus make forms of interaction desirable, which in turn facilitates increased benefits in problem-solving capacities. Taken in this light, one might also deduce that certain forms of bilingualism might suffer from reduced performance scores as a result of situations in which interpersonal factors are deleterious to that individual's motivation. One can, for example, take the differing scores mentioned previously in this article, relating to the indication that English-Chinese participants performed less well than the English-Spanish bilinguals and monolinguals on several verbal intelligence tests. Using the sociocultural theory, one can primarily perceive this result as one that is rooted in the manner in which those particular learners acquired the second language, and whether their motivational drives were affected by the social circumstances, above any other eternal factor.

\section{Conclusion}

To summarise, the fields of education psychology, neuro-cognitive sciences and applied linguistics have seen a multitude of studies, which have comfortably drawn significant correlations between bilingualism and increased cognitive performance. However, these benefits do not manifest themselves in a ubiquitous manner. Indeed, while a vast amount of literature has suggested that an individual's general control mechanism, cognitive resources, and metacognitive awareness may be increased as a result of bilingualism, there are also areas which have provided routinely inconsistent results. Metalinguistic awareness, for example, is said to show positive correlations between bilingualism and phonetic awareness, but it has failed to provide evidence that these benefits carry on past the first grade. As a result, the question of age has remained an issue of great contention. In an attempt to provide a holistic theory of age-related critical periods of learning, theorists have posited models in which critical periods are followed by a decline and a flat-line in bilingualism's cognitive benefits over time. These too, however, have been difficult to prove. Thus, the answer could be found in an in-depth look at the specific socio-cultural factors, which are involved, in the learning process of an individual. The 
socio-cultural theory, at its core, indicates that individuals navigate their reality through higher-level cultural tools. These tools, which include language, are mediated and internalized through a complex process of socialization- and as such may produce very different results depending on the individual's context-dependent circumstances. Thus, it is possible to conclude that, while certain cognitive benefits arising from bilingualism may appear with less regard for context circumstance, the range of cognitive benefits that may result as a product of SLA may also be an important outcome of a combination of elements including age and socio-cultural factors.

\section{References}

Adescope, O./ T. Lavin/ T. Thompson/ C. Ungerleider (2010), A Systematic Review and Meta-Analysis of the Cognitive Correlates of Bilingualism. In: Review of Educational Research. 80 (2), 207-245.

Bialystok, E./ F.I. Craik/ M. Freedman (2007), Bilingualism as a protection against the onset of symptoms of dementia. In: Neuropsychologia, 45

Bialystok, E./ S. Majumder/ M.M. Martin (2003), Developing phonological awareness: Is there a bilingual advantage? In: Applied Psycholinguistics, 24(01), 27-44.

Birdsong, D. (2006), Age and second language acquisition and processing: A selective overview. In: Language Learning, 56, 9-49.

Bruck, M./ F. Genesee (1995), Phonological awareness in young second language learners. In: Journal of child Language, 22(02), 307-324.

Cooper, P./ D. McIntyre (1996), Effective teaching and learning: teachers' and students' perspectives. McGraw-Hill International.

Guilford, J.P./ P.R. Christensen (1967), The One-Way Relation Between Creative Potential and IQ*. In: The Journal of Creative Behavior, 7(4), 247-252.

Hakuta, K./ E. Bialystok/ E. Wiley (1994), Critical evidence a test of the critical-period hypothesis for second-language acquisition. In: Psychological Science, 14(1), 31-38.

Hommel, B. (2011), Attention and spatial stimulus coding in the Simon task: a rejoinder to van der Lubbe and Abrahamse (2010). In: Actapsychologica, 136(2), 265-268.

Johnson, J.S./ E.L. Newport (1989), Critical period effects in second language learning: The influence of maturational state on the acquisition of English as a second language. In: Cognitive psychology, 21(1), 60-99.

Kemp, C. (2007), Strategic processing in grammar learning: Do multilinguals use more strategies? In: International Journal of Multilingualism, 4(4), 241-261.

Lantolf, J.P./ S.L. Thorne (2006), Sociocultural theory and second language acquisition. In: Explaining second language acquisition, 201-224.

Lenneberg, E.H./ N. Chomsky/ O. Marx (1967), Biological foundations of language (Vol. 68). New York.

Long, M. H. (1990), Maturational constraints on language development. In: Studies in second language acquisition, 12(03), 251-285.

Mednick, M.T. (1962), Research creativity in psychology graduate students. In: Journal of Consulting Psychology, 27(3), 265. 
Morton, J.B./ S.N. Harper (2007), What did Simon say? Revisiting the bilingual advantage. In: Developmental Science, 10, 719-726.

Peal, E./ W.E. Lambert (1962), The relation of bilingualism to intelligence. In: Psychological Monographs: General and Applied, 76, 1-23.

Pinker, S. (1994), The language instinct: The new science of language and mind (Vol. 7529). Penguin UK.

Ransdell, S./ M.L. Barbier/ T. Niit (2008), Metacognitions about language skill and working memory among monolingual and bilingual college students: When does multilingualism matter? In: International Journal of Bilingual Education and Bilingualism, 9(6), 728-741.

Ricciardelli, L.A. (1992), Bilingualism and cognitive development in relation to threshold theory. In: Journal of psycholinguistic research, 21(4), 301-316.

Scovel, T. (2000), A critical review of the critical period research. Annual Review of Applied Linguistics, 20, 213-223.

Seliger, H.W. (1978), Implications of a multiple critical periods hypothesis for second language learning. In: Second language acquisition research: Issues and implications, 11-19.

Valenzuela, M.J./ P. Sachdev (2006), Brain reserve and dementia: a systematic review. In: Psychological medicine, 36, 441-454., 459-464.

Vygotsky, L.S. (1978), Mind in society: The development of higher psychological processes. Harvard.

Yelland, G.W./ J. Pollard/ A. Mercuri (1993), The metalinguistic benefits of limited contact with a second language. In: Applied Psycholinguistics, 14(04), 423-444. 